\title{
La fluidez conceptual en la interlengua escrita de aprendientes alemanes de español como lengua extranjera
}

\author{
Carmen Mateo Gallego (Heilbronn)
}

\begin{abstract}
This paper focuses on the written interlanguage of German college students studying Spanish as a Foreign Language in four different levels (A2-C1). In order to observe the evolution of conceptual fluency, a total number of sixty participants wrote an essay about their Spanish studies without previous instruction on the Theory of Conceptual Metaphor (Lakoff/Johnson 1980). The metaphorical density index was measured with special attention paid to the differences and similarities between the German and Spanish semantic conceptual systems and the metaphors used in each stage of learning. The results show that the L1 plays a fundamental role in the typology of metaphors, while quantitative factors such as the metaphorical density index can also vary depending on the target language and the topics of the essays. Therefore, conventional metaphors play a fundamental role in foreign language learning, as the most significant examples in terms of lack of conceptual fluency have been caused by copying linguistic structures from conventional German metaphors into the target language.
\end{abstract}

\section{$1 \quad$ Introducción}

Los fundamentos de la Teoría de la Metáfora Conceptual (TMC) de Lakoff/Johnson (1980) se extendieron rápidamente a distintas ramas de la lingüística que aprovecharon sus preceptos tanto para crear nuevos postulados como para renovar los fundamentos de teorías anteriores. Marcel Danesi (1986) y Graham Low (1988) son los iniciadores de un enfoque que reconoce el potencial didáctico de la TMC en el ámbito de la enseñanza-aprendizaje de segundas lenguas. Según los principios de este enfoque, las metáforas conceptuales que se plasman en las producciones lingüísticas de los hablantes nativos son cruciales en la enseñanza de segundas lenguas. Un aprendizaje basado en la metáfora conceptual contribuye a que los aprendientes entiendan y reproduzcan correctamente las expresiones lingüísticas metafóricas que abundan en la lengua que están aprendiendo. En el caso del español como lengua extranjera (ELE), el aprendiente debe ser consciente de que las personas se pueden empapar de cultura, que una teoría puede impregnar el pensamiento de una época o que se pueden verter informaciones en una declaración. Esto se debe a que tanto el conocimiento como la cultura se conceptualizan otorgándoles las cualidades de un líquido. 
El propósito que persigue el enfoque didáctico de la TMC es que los aprendientes produzcan un discurso más natural y cercano al de los hablantes nativos. Tanto la falta de naturalidad como el alto grado de literalidad que presentan las producciones de los aprendientes se deben a una carencia de competencia metafórica (Danesi 1988) referida a la capacidad para entender y producir metáforas en una lengua extranjera. Según los defensores de este enfoque, esta carencia es la que lleva a los aprendientes a utilizar estructuras de su lengua nativa cuando se expresan en una lengua extranjera, produciendo así un discurso antinatural. A raíz del concepto de competencia metafórica, unos años más tarde, Danesi (1992) acuñó asimismo el concepto de fluidez conceptual en contrapartida a la fluidez que se adquiere en el plano verbal. Desde el surgimiento de estos dos conceptos, han sido numerosas tanto las propuestas didácticas que contribuyen a un mejor conocimiento del sistema conceptual que subyace en la lengua meta, como las teorías centradas en su correcta adquisición. Por ejemplo, Russo (1997) pone manifiesto a través de la Hipótesis de la Fluidez Conceptual que el aprendiente pasa por una serie de estadios intermedios hasta que llega a la adquisición plena de la fluidez conceptual, que se corresponde con el nivel avanzado de la lengua. Esta idea consta además en numerosos estudios posteriores (Littlemore et al. 2010, 2014; Đoan Ha 2015; MacArthur 2017 y Nacey 2017).

Teniendo en cuenta que la Teoría de la Metáfora Conceptual (TMC) no es tomada en consideración ni en los manuales ni en el Marco Común Europeo de Referencia para las lenguas (MCER), este estudio tiene como objetivo analizar el índice de densidad metafórica que presenta la interlengua ${ }^{1}$ escrita de estudiantes de español como lengua extranjera (ELE) de cuatro niveles consecutivos. De este modo, se podrán sacar conclusiones sobre las metáforas que usan los aprendientes dependiendo del nivel, los factores que pueden determinar su uso y el papel que juega el idioma alemán, que es su lengua materna.

\section{Estado de la cuestión}

\subsection{Competencia metafórica y fluidez conceptual}

A partir de la segunda mitad del siglo XX, fueron surgiendo trabajos sobre la metáfora que ya apuntaban a su carácter omnipresente en todo tipo de texto y a reivindicar los procesos cognitivos que se plasman en las expresiones metafóricas. Así, en el año 1980, surgió la obra $M e$ taphors we live by (1980) de Lakoff y Johnson que da a conocer la Teoría de la Metáfora Conceptual (TMC). Según los postulados de esta teoría, las metáforas son esquemas de pensamiento que residen en nuestros sistemas cognitivos y se fundamentan básicamente en el entendimiento de una cosa en términos de otra (Lakoff/Johnson 1980: 5).

Las metáforas conceptuales se representan a través de distintos medios como los gestos, la fotografía y el signo lingüístico. Este último medio de representación es considerado además el método de análisis de metáforas conceptuales más fiable y más utilizado desde el surgimiento de la TMC: "From the earliest writing of CMT (Conceptual Metaphor Theory) to the present,

\footnotetext{
${ }^{1}$ Este término fue acuñado por Selinker (1972) y hace alusión al sistema lingüístico de los aprendientes de una lengua extranjera que, entre otras particularidades, se caracteriza también por contener incorrecciones.
} 
linguistic metaphors have been the main type of evidence provided in support of the existence of conceptual metaphors" (Deignan 2017: 102).

Las metáforas conceptuales siguen el esquema A ES B, por ejemplo EL FUTURO ES DELANTE y EL PASADO ES DETRÁS, y por convención se escriben en mayúscula. La razón que lleva a la escritura de las metáforas conceptuales en mayúscula es el objetivo de diferenciarlas claramente de las expresiones lingüísticas metafóricas, también llamadas metáforas lingüísticas, que surgen de ellas. Por ejemplo, la metáfora conceptual que se ha expuesto anteriormente da lugar a expresiones lingüísticas metafóricas como hay que mirar hacia delante en referencia al futuro o hay que echar la vista atrás cuando nos referimos al pasado. La conceptualización espacio-temporal adquiere gran importancia en los estudios que comparan la metáfora como fenómeno interlingüístico, especialmente en lenguas provenientes de culturas lejanas. Si bien en las lenguas románicas y germánicas la metaforización del tiempo es horizontal y se representa mediante las dicotomías espaciales delante-detrás, en la cultura china, el eje temporal es vertical. Por lo tanto, para los hablantes de chino mandarín EL PASADO ES ARRIBA y EL FUTURO ES ABAJO (Bylund/Konke 2015: 114).

Tanto la metáfora como la metonimia guardan una estrecha relación con el principio teórico de la corporeización o embodiment mediante el cual los entes abstractos, dado que son físicamente inaccesibles, necesitan de otro ente con características físicas para adquirir significado. Por esta razón, la mayoría de las metáforas conceptuales tienen una base corporeizada (Gibbs 2006) y una abstracta a la que traspasarle características. El principio de la corporeización muestra un alto potencial en la didáctica de segundas lenguas². Como afirma Llopis García (2016: 37), especialmente en la enseñanza de español como lengua extranjera (ELE) es una de las herramientas más efectiva no solo por las obvias ventajas que ofrece para enseñar contenidos léxicos, sino especialmente cuando se introducen y explican formas y construcciones gramaticales más abstractas.

El cambio de paradigma que trajo consigo la TMC marcó un antes y un después en la investigación sobre la metáfora. Como afirma Sullivan (2013: 1) “The proposal that metaphors might be conceptual structures, not mere linguistic decoration, revolutionized metaphor investigation”. Por lo tanto, el hecho de que las producciones lingüísticas de los hablantes estén repletas de expresiones metafóricas provenientes de metáforas conceptuales pronto encontró aplicación en el ámbito de la enseñanza-aprendizaje de segundas lenguas. Como afirma Acquaroni (2008: 131): "Los trabajos centrados en este campo de investigación tienen en común tres características fundamentales: comparten el punto de vista de la TMC de Lakoff/Johnson (1980), defienden el potencial comunicativo que brinda la metáfora y por lo tanto, han visto el potencial didáctico que ofrece en la enseñanza de segundas lenguas". Principalmente las aportaciones de Danesi (1986, 1991, 1992, 1994, 2003, 2016), Low (1988), Russo (1997) Littlemore (2001b), Boers (2001) y Acquaroni (2007) han contribuido a sentar las bases terminológicas del enfoque didáctico centrado en la metáfora conceptual.

\footnotetext{
${ }^{2}$ Tanto el término segunda lengua como lengua extranjera recibirán el mismo tratamiento a lo largo de este trabajo siendo consciente de la diferencia tipológica existente entre un término y otro. Esto se debe a que la literatura de este campo se centra en la adquisición de lenguas distintas a la materna, lo que engloba los dos términos.
} 
El concepto de competencia metafórica $(\mathrm{CM})$ aplicado a aprendientes de segundas lenguas surgió a raíz de los trabajos de Marcel Danesi (1988), que le dio el nombre de metaphorical competence y de Graham Low (1988), que la llama metaphoric competence. A pesar de utilizar una nomenclatura que difiere levemente, los dos hacen referencia al conjunto de capacidades, conocimientos y destrezas que debe poseer el aprendiente para adquirir, producir y comprender metáforas en una determinada lengua extranjera (Litlemore/Low 2006).

La mayoría de los estudios posteriores que siguieron esta línea de investigación (Valeva 1999; Boers 2000; Littlemore 2001; Kecskés/Papp 2000b) toman en cuenta únicamente a Danesi (1988) como introductor del concepto de CM. Sin embargo, tanto su obra fundacional como sus trabajos más tempranos son criticados por no ofrecer una definición clara del término (Valeva 1996: 24) y basarse más bien en una crítica pedagógica a la poca importancia que recibe la metáfora en el aula. Esto ocasiona que las producciones de los estudiantes no gocen de la naturalidad que caracteriza las producciones de los hablantes nativos. Las aportaciones de Low (1988) a la CM también fueron clave para sentar las bases de este nuevo concepto ya que afirma que para él, es preciso que el aprendiente tenga un conocimiento profundo sobre el funcionamiento de la TMC y de las conexiones entre los dominios implicados en la creación metafórica. Además, recalca que estas habilidades pueden variar dependiendo de cada individuo y están relacionadas con la competencia sociolingüística.

El lugar que ocupa la CM dentro de la competencia comunicativa ha sido un tema tratado por diversos autores. A partir de los 90, los trabajos de Danesi abandonan el modelo de competencia comunicativa de Canale (1983) en el que se basó su trabajo de 1986 para hacer una clara distinción entre la competencia comunicativa, la competencia metafórica y la competencia gramatical. De igual manera, unos años más tarde, acuña el término fluidez conceptual (FC). Según Danesi (1992), la fluidez en el plano conceptual se da de manera inconsciente en los hablantes nativos de una lengua y va más allá del plano verbal, está relacionada con el conocimiento del sistema conceptual que subyace en una lengua. Por lo tanto, es preciso adquirir fluidez conceptual para saber hacer conexiones correctas entre los dominios de lo abstracto y lo concreto. "Los discursos producidos por el estudiante parecen seguir el flujo conceptual de la lengua nativa (native-language conceptual flow) que se `viste`, por así decirlo, de gramática y vocabulario de la LM" "Acquaroni 2008: 165). Como ya señalaba Danesi (1992: 490), los aprendientes piensan en su lengua materna pero hablan en una lengua meta. Es por eso que, debido a una carencia de FC, crean estructuras calcadas de su lengua materna.

Con la siguiente tabla (1), Acquaroni (2007: 260) ilustra la visión que defiende Danesi (1992, 1994, 1998, 2002) respecto al papel que ocupan la CM y la FC en relación con las demás competencias:

\begin{tabular}{|c|c|c|}
\hline competencia gramatical & competencia comunicativa & competencia metafórica \\
\hline \multicolumn{2}{|c|}{ FLUIDEZ VERBAL } & FLUIDEZ CONCEPTUAL \\
\hline
\end{tabular}

Tabla 1: Fluidez conceptual y competencia metafórica

\footnotetext{
${ }^{3}$ Lengua meta.
} 
El tratamiento independiente que le da Danesi a la CM en relación con la competencia comunicativa no está exento de críticas. Valeva (1996: 23) considera que los conceptos de CM y FC no pueden tratarse de manera aislada y defiende que la fluidez conceptual es necesaria para poder comunicarse de manera fluida en la lengua meta y por consiguiente, está incorporada dentro de la fluidez verbal. Al igual que Valeva (1996), Litlemore/Low (2006) no separan la CM de la competencia comunicativa sino que la integran dentro del concepto de competencia comunicativa (CC) de Bachman (1990). Además, estos dos autores defienden que el concepto de CM incluye no solo el conocimiento de la metáfora, sino también la capacidad para usarla y las habilidades necesarias de los aprendientes que quedaron descritas en el trabajo de Low (1988). Por lo tanto, el punto de vista de Littlemore/Low (2006) forma parte de una visión integradora de la CC en las corrientes de enseñanza y evaluación de segundas lenguas.

\section{$2 \quad$ El ciclo de vida de las metáforas}

Las metáforas recorren un ciclo de vida que va desde la metáfora novedosa hasta la metáfora muerta. Dentro de este planteamiento impera la heterogeneidad de opiniones ya que existen clasificaciones que van desde la metáfora novedosa hasta la metáfora muerta pasando por la metáfora convencional, dormida o en fase de muerte. Charteris-Black (2004: 18-19) afirma que la gran dificultad que conlleva el establecimiento de un ciclo de vida de las metáforas reside especialmente en fijar el punto cronológico concreto en el que una metáfora pasa por los distintos estadios de vida.

Una metáfora es novedosa cuando causa un efecto de extrañeza o sorpresa en el receptor a causa de no estar integrada plenamente en el repertorio lingüístico de los hablantes. Después de ser novedosa, con el paso del tiempo su uso se hace habitual, por lo tanto, se convierte en una metáfora convencional, también llamada semilexicalizada o tradicional. Esto significa que aunque se use con asiduidad, los hablantes son conscientes de su valor metafórico. Por ejemplo, de la metáforaUNA DISCUSIÓN ES UNA GUERRA, surgen expresiones lingüísticas como atacó mis argumentos o se defendió diciendo que no había sido él. En estos casos, los hablantes reconocen fácilmente palabras pertenecientes al campo semántico de los conflictos bélicos para referirse a las discusiones sin necesidad de acudir a fuentes de consulta. Este tipo de metáfora recibe comúnmente en la literatura el mismo tratamiento que la metáfora muerta aunque exista una diferencia palpable entre ambas. La distinción principal entre las dos reside en que la metáfora muerta, lexicalizada o fosilizada es aquella que se ha convencionalizado de tal manera que la relación metafórica que subyace en ella ya no es reconocible a no ser que se recurra a fuentes de consulta. Trim (2007: 147) ejemplifica este planteamiento mediante la palabra pedigrí, que proviene del francés pied de grue, es decir, el pie de una grúa. La explicación reside en que antiguamente, los pies de las grúas se asemejaban a las raíces de los árboles, y de ahí, ese significado se ha derivado a los árboles genealógicos dando lugar a una metáfora muerta. Sin embargo, la relación metafórica no está 'a simple vista' sino que es preciso buscarla. Lo mismo se puede aplicar a preposiciones. Por ejemplo, cuando se emplea la frase hablaron sobre economía, la preposición sobre tiene un significado primario físico que se correspondería con encima de. No obstante, ha pasado a formar parte de la conciencia comunicativa de los hablantes con sentido de acerca de, como ocurre en el caso de las expresiones idiomáticas. 
Danesi (1986) reconoce la importancia que tienen las metáforas muertas para los aprendientes de segundas lenguas. Sin embargo, destaca que es la capacidad para producir metáforas novedosas la que supone una estrategia discursiva y comunicativa trascendental. Además, afirma que mientras las expresiones idiomáticas contribuyen a la correcta consolidación del léxico, "es en el campo de la creación de metáforas novedosas donde el aprendiz se verá realmente involucrado en una estrategia discursiva que es esencial para el desarrollo de la competencia comunicativa" (Danesi 1986: 4). Johnson/Pascual-Leone (1989), Paivio/Walsh (1993) y Littlemore (2001a) también tienden a dotar a las metáforas novedosas de un papel más relevante dentro del desarrollo de la CC. Esta última autora, basándose en la teoría de las ocho inteligencias múltiples de Gardner (1983)4, propone una novena inteligencia metafórica que describe como la capacidad que tiene el aprendiente de entender y producir metáforas novedosas en una lengua extranjera. De igual manera, existe otra línea de investigación que se centra únicamente en el estudio de la adquisición de expresiones idiomáticas provenientes de metáforas muertas (Cooper 1999; Bortfield 2002 y Muro 2014).

En el presente trabajo, se analizarán todo tipo de metáforas independientemente del ciclo de vida en el que se encuentren. De este modo, se podrá constatar el papel que desempeñan para el correcto desarrollo de la FC dependiendo de si se trata de metáforas novedosas, convencionales o muertas.

\subsection{La metáfora como fenómeno interlingüístico}

Independientemente del ciclo de vida en el que se encuentren las metáforas, una vez que se plasman a través del lenguaje, se pueden representar de diversas maneras en distintos idiomas. Para ejemplificar esta afirmación, Llopis García et al. (2012: 38) compara tres expresiones metafóricas provenientes del español, inglés y alemán: criar malvas en español, to be pushing up the daisies en inglés (empujar hacia arriba las margaritas) o die Blumen von unten angucken en alemán (mirar las flores desde abajo). Estas expresiones metafóricas cuya forma linguística cambia, utilizan la botánica para expresar la misma idea: estar muerto. Una de las premisas fundamentales del nuevo paradigma que introdujo la TMC es que las metáforas conceptuales no pueden ser identificadas con patrones lingüísticos fijos como se había venido haciendo desde la perspectiva retórica tradicional (Acquaroni 2007: 438).

La distinción entre la metáfora cognitiva y su forma lingüística es fundamental para determinar si en todos los idiomas se da el mismo proceso de creación metafórica. La combinación entre la metáfora conceptual y la representación que adquiere en distintas lenguas es un enfoque que cobró fuerza a finales de la década de los 90, cuando proliferaron los estudios de la metáfora conceptual desde una perspectiva interlingüística. Así pues, existen trabajos que se centraron en determinar las combinaciones posibles entre las conceptualizaciones y las formas lingüísticas en las que se plasman. Por ejemplo, Deignan/Gabryś/Solska (1997) afirman que existen cuatro opciones posibles. La primera representa la simetría total entre las dos lenguas, por lo

\footnotetext{
${ }^{4}$ La inteligencia según este autor se basa en conjunto de múltiples inteligencias interrelacionadas. Entre ellas se encuentran las siguientes: lingüística, lógico-matemática, espacial, musical, corporal-cenestésica, intrapersonal, interpersonal y naturalista.
} 
tanto, las dos comparten la misma forma lingüística y la misma conceptualización. En la segunda combinación, las dos lenguas comparten la misma metáfora conceptual pero no la misma forma lingüística. En la tercera, las formas lingüísticas tienen un sentido literal similar pero provienen de una metáfora conceptual distinta y por último, se puede dar también la falta total de simetría entre metáforas conceptuales y lingüísticas. Esta línea de investigación ha proliferado a lo largo de las décadas con trabajos como los de Kövceses (2005), Al-Hasnawi (2007) y Maalej (2008) centrados en el análisis de las combinaciones posibles entre metáforas conceptuales y lingüísticas en distintos idiomas.

En el caso del alemán y del español, los patrones de conceptualización son muy similares. Sin embargo, existen numerosas metáforas conceptuales que dan lugar a formas lingüísticas distintas en ambos idiomas. Por ejemplo, la metáfora conceptual LA SOBERBIA ES ARRIBA, en el idioma español deriva en la expresión lingüística metafórica llevar la cabeza alta. En el caso del alemán, se emplea la nariz como signo de soberbia a través de la expresión die Nase hochtragen, es decir, llevar la nariz alta (Mellado Blanco 1999: 334).

Acquaroni (2007) afirma que las metáforas conceptuales EMPEZAR ES LUZ y TERMINAR ES OSCURIDAD también tienden a producir errores relacionados con la falta de competencia metafórica en aprendientes alemanes de ELE. Para ejemplificar esta falta de isomorfismo entre las formas lingüísticas a las que dan lugar estas conceptualizaciones, toma como ejemplo la siguiente oración: El próximo viernes se apaga* el curso (ibíd. 167). Esta frase corresponde a un aprendiente alemán de ELE, cuyo uso erróneo del verbo apagar en lugar de acabar está ocasionado por la proximidad fonética entre ambos verbos. Además de esta causa, la autora argumenta que se trata también de una carencia de competencia metafórica ya que en alemán, se utiliza el verbo ausgehen con sentido de apagarse cuando se trata por ejemplo de una vela, o para expresar que un proceso llega a un final como en las expresiones gut/schlecht ausgehen (acabar bien/mal). Por lo tanto, la hipótesis de Acquaroni (2007: 168) que lleva al aprendiente a utilizar el verbo apagarse en español residiría en una interferencia de la lengua materna. Sin embargo, en este trabajo se defiende la proximidad léxica entre acabar y apagar como única causa de la incorrección del aprendiente, ya que el verbo ausgehen no se emplea en alemán para expresar que un curso se acaba. En este caso, se utilizarían los verbos enden o aufhören, que corresponden a terminar o acabar en español.

Al igual que existen autores que se decantan por los factores de índole conceptual como única causa de la antinaturalidad de la interlengua de los aprendientes, existen otros enfoques que recalcan que esta peculiaridad es más un problema de índole lingüística que conceptual como por ejemplo Philip (2005), que le da el nombre de ill-formed phraseology. De igual manera, Lakoff (1993: 205) afirma que existen conceptos que nuestra mente aprehende directamente sin pasar por el mecanismo metafórico. Por lo tanto, no toda la falta de naturalidad en los escritos de los aprendientes estará ocasionada por una carencia de fluidez en el plano conceptual, sino que también entran en juego factores lingüísticos y extralingüísticos que afectan a esta falta de precisión. Por ejemplo, una de las causas extralingüísticas más extendidas en la literatura de este campo es el alto grado de literalidad que presentan los libros de texto, a lo que Danesi (1995) se refiere como textbook literalness. Boers (2014) afirma también que a pesar de la proliferación de los estudios que revelan la necesidad de un enfoque didáctico de segundas 
lenguas más centrado en aspectos cognitivos, todavía no se han plasmado en los libros de texto. De esta manera, queda evidenciada la brecha que existe entre los estudios teóricos y su aplicación práctica.

Si bien en el ámbito de ELE no hay constancia de estudios que analicen el tratamiento de la metáfora en los libros de texto, Acquaroni (2007: 137) afirma que en los manuales de ELE, el lenguaje metafórico que aparece es en su mayoría idiomático y está organizado a partir de "criterios semánticos y no cognitivos, como si se tratara de expresiones aisladas sin ningún tipo de motivación conceptual que las vincule”. Nacey (2017: 509) afirma que este problema se debe a que en el MCER todavía se mantiene la visión tradicional de la metáfora como figura retórica y no como elemento de la cognición. De esa manera, la producción de materiales y libros de texto que se apoyan en las directrices que marca el MCER siguen sin prestarle atención a la metáfora como un fenómeno intrínseco al pensamiento humano. Por lo tanto, es la voluntad expresa del docente lo que lleva a aplicar los preceptos de la TMC en clase de lenguas extranjeras y a trabajar la competencia metafórica de los aprendientes. Dependiendo de las similitudes de los sistemas conceptuales que rigen la lengua materna y la lengua meta, las expresiones metafóricas de ambas lenguas gozarán de un alto grado de isomorfismo (Danesi 2003: 66). Esto posibilitará el entendimiento correcto de la metáfora de la lengua extranjera y contribuirá a que las creaciones metafóricas de los aprendientes sean adecuadas. Sin embargo, cuando se conceptualiza un dominio de manera distinta, pueden surgir asimetrías. Por eso, es preciso conocer el sistema conceptual proveniente de la lengua que se está aprendiendo. Danesi (1992: 491) afirma que la competencia avanzada de una lengua se alcanza cuando en el sistema lingüístico de los aprendientes se equiparan la fluidez verbal y la fluidez conceptual. Además, otorga un principal protagonismo al papel de la lengua materna en el aprendizaje de segundas lenguas. Por lo tanto, la teoría de la FC reactiva el papel del Análisis Contrastivo (AC) como técnica heurística pedagógica, corriente que surgió en el contexto del Behaviorismo de los años 50 y culpaba a la lengua materna de todos los errores cometidos en las producciones de los aprendientes. Sin embargo, la particularidad se centra en que esta vez los principios del AC están centrados en el sistema conceptual y no en el verbal (Acquaroni 2008: 167). Del mismo modo, la Hipótesis de la Fluidez Conceptual de Russo (1997) defiende que la lengua materna adquiere un papel crucial a la hora de acceder al sistema conceptual de la lengua meta. Esta hipótesis consta de una escala de cinco fases en las que el aprendiente, partiendo de estructuras lingüísticas calcadas del sistema conceptual nativo, va accediendo y comprendiendo poco a poco el sistema conceptual de la lengua meta. Así, logra que sus producciones sean más naturales y se asemejen a las de los hablantes nativos. La última etapa de Russo (1997) es la de la adquisición plena de FC, en la que la traducción literal no es necesaria porque el aprendiente ya conoce el sistema conceptual de la lengua meta y las formas lingüísticas en la que se plasma.

Littlemore et al. (2012) llevaron a cabo un estudio con aprendientes alemanes y griegos de inglés como lengua extranjera de niveles comprendidos entre el A2 y el C2. El objetivo era constatar cómo varían las metáforas dependiendo del nivel del aprendiente teniendo en cuenta valores cuantitativos y cualitativos como la función de la metáfora, el tipo de palabra en la que se representa y la lengua materna de los aprendientes. En las redacciones de los estudiantes de niveles más bajos cuya lengua materna es el alemán, se observa una tendencia muy pronunciada a calcar las estructuras de la lengua materna. Esta tendencia disminuye a medida que avanza el 
nivel. Sin embargo, en los niveles más avanzados, los errores ocasionados por metáforas están fuertemente motivados por la lengua materna. Por ejemplo, el siguiente error: is everything running *smooth (Littlemore et al 2012: 25) en vez del uso correcto de smoothly radica según las autoras en la dificultad de los hablantes nativos de alemán de distinguir entre formas adjetivales y adverbiales. Los resultados mostraron también que efectivamente, los aprendientes son capaces de producir más metáforas en un nivel más avanzado. Además, constatan que en el nivel B2, cuantas más palabras con carga metafórica emplean los aprendientes, más errores producen.

\subsection{El cálculo de la densidad metafórica}

La primera propuesta del cálculo de este índice proviene de Danesi (1991: 192; 1995: 12), que afirma que para determinar el grado de fluidez conceptual, es preciso medir el índice de densidad metafórica de cada texto:

This simply measured the number of metaphorical sentences as a percentage of the total number of sentences written. A metaphorical sentence was defined as a token or instantiation of underlying conceptual system: e.g. an orientation metaphor, an entity metaphor etc.

(Danesi 1995: 12)

Si bien Danesi, mediante el uso del término metaphorical sentence, se aleja de la terminología preestablecida en la TMC, los trabajos de autores posteriores que toman su definición, como Kecskes/Papp (2000a: 100; 2000b: 108), lo equiparan con el término metaphorical expression que establece la TMC. Por lo tanto, la fórmula que emplea Danesi para medir la densidad metafórica se basa en el número total de expresiones lingüísticas metafóricas dividido entre el número total de oraciones y multiplicado por cien. Esta fórmula se ha usado en estudios posteriores como el de Russo (1997: 69) con aprendientes de italiano como lengua extranjera. Además, hace una reflexión sobre el cálculo de la DM afirmando que se trata de un valor cuantitativo de frecuencia relativa y nunca se debe tomar en cuenta como un valor absoluto.

El cálculo de la densidad metafórica de Danesi ha sido empleado mayoritariamente para analizar muestras de interlengua (IL) de aprendientes de inglés como lengua extranjera (Kecskés/Papp 2000b; Hashemian/Nezhad 2007). Los trabajos que han ido surgiendo a principios del siglo XXI y que aplican el cálculo de la DM, toman en cuenta el número de palabras y no la oración como Cameron (2003), que utiliza el término metaphor density en lugar de metaphorical density, al igual que Littlemore et al. (2014) y Acquaroni (2007). Esta última autora crea una fórmula que afina más todavía en el concepto ya que en vez de aplicar el número de metáforas lingüísticas, se basa en el número de vehículos metafóricos, "más allá de que cada metáfora lingüística esté constituida por una o varias palabras, una cláusula o toda una oración" (Acquaroni 2007: 478). La razón que ofrece la autora para el análisis del número de palabras en vez del número de oraciones es que al tratarse de muestras de IL, y debido a los errores que afectan al ámbito sintáctico, es difícil determinar con exactitud todas las estructuras oracionales de cada texto. 
A partir de las propuestas que surgieron para calcular el índice de DM, han aparecido trabajos que se centran no solo en el estudio de la cantidad de las metáforas que producen los aprendientes sino que estudian también la distribución que adoptan dentro de los conjuntos textuales a través de una operación con el nombre moving metaphoric density (Littlemore et al. 2012; 2014). De este modo, es posible identificar clusters metafóricos. Según Cameron/Stelma (2004: 107), este fenómeno se da cuando en el discurso tanto oral como escrito de repente se producen múltiples metáforas a la vez en comparación con otros puntos en los que las metáforas son muy escasas.

Dado que el objetivo de este trabajo no se centra en la distribución sino que atiende a la cantidad y a la tipología de las metáforas y su comparación con el sistema conceptual de la lengua materna, se aplicará la fórmula de la DM de Acquaroni (2007). Así, se podrá hallar la densidad metafórica de los escritos y se tendrá en cuenta asimismo el número de palabras en vez del número de oraciones. La razón de esta elección se fundamenta en el mismo criterio que expone la autora; las muestras de IL presentan incorrecciones sintácticas que dificultan el recuento total del número de oraciones de un escrito.

\subsection{Identificación de las expresiones lingüísticas metafóricas}

Una de las principales críticas que se desprende de la fórmula de la DM que propuso Danesi (1995) es que no menciona en ningún capítulo de su obra cómo se lleva a cabo la identificación de expresiones lingüísticas metafóricas (Nacey 2013). Asimismo, es preciso recalcar que tanto la obra fundacional de la TMC, como los trabajos que contribuyeron a su consolidación tampoco proporcionan pautas de identificación de metáforas linguiísticas. Por lo tanto, los primeros trabajos sobre la metáfora que se centraron en el enfoque cognitivo emplean principalmente el método deductivo para identificar metáforas lingüísticas. Es decir, daban por hecho la existencia de metáforas conceptuales determinadas, como por ejemplo LA FELICIDAD ES ARRIBA, y a partir de ellas, buscaban en el texto expresiones lingüísticas metafóricas en las que se reflejaba esa conceptualización como ¡Qué subidón de alegría!

Este tipo de identificación conlleva según Herrmann (2013: 73) a dos problemas principales. En primer lugar, este método tiene una base principalmente intuitiva, es decir, le sigue otorgando protagonismo a la subjetividad del investigador. En segundo lugar, con este método es más fácil pasar por alto metáforas lingüísticas que por medio de métodos con pautas precisas. Por lo tanto, a partir de finales de la década de los 90, surgen trabajos que empiezan a recalcar la necesidad de un enfoque de la metáfora que tenga en cuenta la lengua en uso y sea de corte inductivo (Steen 1999; Cameron/Low 1999; Cameron 2003; Cameron/Deignam 2006). Así, en el año 2007, el Grupo Pragglejaz, formado por diez expertos en el ámbito de la metáfora, crea el Metaphor Identification Prodecure (MIP), aplicable a la identificación de metáforas lingüísticas en todo tipo de textos. Como afirman los integrantes de este grupo: "metaphoric language demands that metaphor scholars explore `metaphor in the wild` as speakers and writers produce it in varying contexts" (Grupo Pragglejaz 2007: 1). La peculiar nomenclatura de este grupo proviene de unir la primera letra de los nombres de los investigadores que participaron en este trabajo: Peter Crisp, Ray Gibbs, Alan Cienki, Graham Low, Gerard Steen, Lynne Cameron, Elena Semino, Joe Grady, Alice Deignan y Zoltan Kövecses. 
Los pasos a seguir del método MIP para la identificación de metáforas son los siguientes (Grupo Pragglejaz, 2007: 3):

1. Leer todo el texto para comprender el sentido general.

2. Determinar las unidades léxicas que contiene el texto o el discurso. Es decir separar el texto palabra por palabra.

3. a) Establecer el significado de cada unidad léxica (UL) dentro del contexto particular en el que aparecen. Hay que tener en cuenta también las unidades léxicas anteriores y posteriores. b) Determinar si cada una de estas unidades léxicas tiene un significado básico (SB) más actual en otros contextos que en el presente contexto. Los significados básicos de una UL no son necesariamente los más frecuentes.

Dichos significados básicos son:

- Más fáciles de imaginar a través de los sentidos.

- Más precisos.

- Más relacionados con la experiencia corpórea.

- Históricamente anteriores.

c) Si la UL tiene un SB actual o contemporáneo en otros contextos, hay que decidir si el significado contextual (SC) contrasta con el SB y se puede entender en comparación con el mismo.

4. Si se dan todas las condiciones anteriores, marcar la UL como metafórica. ${ }^{5}$

A pesar de que el MIP tuvo buena aceptación en el ámbito académico, la falta de un criterio homogéneo de identificación ha complicado la evaluación de constructos teóricos sobre la frecuencia de aparición de metáforas en conjuntos textuales, la organización en el discurso y las posibles relaciones entre el lenguaje metafórico y el pensamiento metafórico (Cameron 2003; Semino/Heywood/Short 2004).

Los propios autores del MIP señalan que no escapa a la subjetividad del investigador, ya que a la hora de marcar una unidad léxica como metafórica, las cuestiones lingüísticas y cognitivas individuales juegan un papel fundamental (Grupo Pragglejaz 2007: 23). Las pautas a seguir en el proceso de identificación de expresiones metafóricas implican una toma de decisiones que puede estar influenciada por variables de índole social, regional, diacrónica, de desarrollo, etc.

En este trabajo, se aplicará el método MIP teniendo en cuenta algunas de las adaptaciones de este método al idioma español que constan en el estudio de Martínez Santiago et al. (2014). Es decir, en el paso número 3 del procedimiento, se buscará la unidad léxica en el diccionario de la Real Academia Española y en caso de que la duda persista, se recomienda el uso de otras fuentes externas que aporten más datos sobre el significado como la herramienta BabelNet.

La crítica principal al MIP es que no proporciona pautas para identificar las expresiones lingüísticas metafóricas directas, sino que el método se centra únicamente en las metáforas indirectas. Estas son las que contienen el término imaginario pero no el término real de la comparación. Por ejemplo, en la expresión nuestras vidas fluyen, existe un sentido metafórico en el verbo fluir, que le otorga al sustantivo la cualidad de un líquido. Sin embargo, no existe un término explícito que apunte al tipo concreto de líquido al que se refiere. Por lo tanto, estamos

\footnotetext{
5 Traducción propia.
} 
ante una metáfora indirecta. Si por el contrario, la expresión metafórica fuera nuestras vidas son ríos que fluyen estaríamos ante una expresión metafórica directa porque ambas partes aparecen explícitas. Para la identificación de metáforas directas, algunos autores se inclinan por el controvertido principio de la incongruencia como Cameron (2003) y Charteris-Black (2004). Estos autores afirman que son palabras que llaman la atención por desentonar con la temática que trata el texto. Además, esta palabra debe estar relacionada con otra palabra que aparece también dentro del conjunto textual en el que se engloba. Pueden estar conectadas mediante cualquiera de las formas conjugadas del verbo ser o tener marcadores comparativos, por ejemplo el adverbio como. Para saber si verdaderamente estas expresiones se corresponden con metáforas lingüísticas, se propone utilizar el is like test (test "es como") de Gibbs (1994). Aunque este autor diseñó el test específicamente para diferenciar las expresiones metafóricas de las expresiones metonímicas, en este caso se usará para la correcta identificación de expresiones metafóricas directas. Si el is like test de Gibbs (1994) crea una frase que no tiene sentido o que no se adapta al objetivo comunicativo específico, no estamos ante una metáfora sino que puede ser una metonimia o una expresión comparativa.

\subsection{Propuestas para el desarrollo de la fluidez conceptual en el aula de segundas len- guas}

Desde la aparición de esta línea de investigación, han surgido asimismo numerosas propuestas didácticas para contribuir al desarrollo de la fluidez conceptual centradas en aprendientes de diversas lenguas. La mayoría de los estudios coinciden en la necesidad de que la TMC se imparta en clase haciendo especial hincapié en la omnipresencia de la metáfora en el pensamiento y por consiguiente, en el lenguaje.

Danesi (1994: 458) se basa en la enseñanza del italiano como lengua extranjera y sugiere estructurar las unidades que componen el temario de los cursos en torno a dominios conceptuales. Esta idea recibe el nombre de conceptual-based syllabus. Con este método, se persigue que los contenidos gramaticales y léxicos del curso estén supeditados al dominio conceptual en el que se centra el temario. Así, la progresión didáctica tendrá lugar dependiendo de los dominios conceptuales que deben ser enseñados en clase. Según Danesi (1994), esta estructuración de contenidos debería extrapolarse igualmente a los libros de texto. Esta propuesta se ha defendido igualmente en diversos trabajos posteriores como el de Liu (2006), Andreou/Galantomos (2008) y Cai (2013).

Littlemore/Low (2006) y Muro (2014) defienden que las imágenes en el aula de segundas lenguas también son una valiosa herramienta para el desarrollo de la FC. Según estos autores, las metáforas visuales facilitan el entendimiento del fenómeno metafórico y permiten al aprendiente reflexionar y crear hipótesis en la lengua meta. Asimismo, el material audiovisual también se ha empleado en estudios como el de Rodríguez/Moreno (2009), que aprovechan el potencial didáctico de películas de Disney para la enseñanza de expresiones idiomáticas relacionadas con las conceptualizaciones LA FELICIDAD ES ARRIBA y LA TRISTEZA ES ABAJO. Este trabajo se centra en la enseñanza del inglés como lengua extranjera y especialmente en aprendientes de corta edad. Esta misma metodología centrada en las películas de Disney también ha sido empleada por Khoshniyat/Dowlatabadib (2014). 
En el ámbito de la enseñanza de ELE, la aplicación de textos literarios ha sido defendida tanto por Lamarti $(2011,2014)$ con aprendientes taiwaneses y chinos, como por Acquaroni (2007), que creó un taller de escritura creativa para aprendientes norteamericanos. Por su parte, Battle (2014) diseña una actividad con aprendientes de ELE independientemente de su lengua materna en la que pone en práctica la propuesta del conceptual-based syllabus a través la metáfora EL AMOR ES UNA GUERRA. A partir de esta conceptualización, se procede a trabajar los contenidos de gramática y vocabulario previstos para esa sesión de clase.

Es preciso recalcar que la instrucción de la TMC en el aula de segundas lenguas entraña una serie de dificultades añadidas. Como ya se ha expuesto anteriormente, los manuales no incluyen actividades ni propuestas didácticas para el desarrollo de la fluidez conceptual de los aprendientes. Además, existen numerosos manuales cuyos contenidos no se estructuran en base a criterios cognitivos. Por consiguiente, debe existir un deseo implícito del docente por instruir los preceptos de la TMC en clase de lenguas extranjeras.

Si bien la fluidez conceptual plena se alcanza en un nivel avanzado de la lengua, esto significa que se ha seguido un proceso de adquisición en el que poco a poco se han ido desterrando los calcos de la lengua materna para pasar a producir un discurso natural en la lengua meta. Por lo tanto, en el presente trabajo, se medirá el índice de DM de los escritos de aprendientes alemanes de ELE de cuatro niveles consecutivos para observar la evolución natural de la fluidez conceptual dependiendo del nivel. Por esta razón, no se realizó ningún tipo de actividad en clase para desarrollar la fluidez conceptual de los participantes del estudio.

\section{$3 \quad$ Metodología}

\subsection{Materiales y procedimientos}

El corpus de esta investigación se compone de redacciones escritas por aprendientes de ELE de los niveles A2, B1, B2 y C1 sin ayuda de fuentes de consulta. En cada uno de los niveles, participaron 15 estudiantes, lo que dio lugar a un total de 60 muestras escritas. La extensión total del corpus es de 8166 palabras, con una media aproximada de 135 palabras por escrito. El tiempo que se les otorgó para la realización de la redacción fue de 15 minutos en total y se les pidió expresamente que escribieran unas 150 palabras. Las muestras escritas se realizaron en la segunda semana del semestre tras haber llevado a cabo una prueba de nivel adaptada a las directrices del MCER y del Diploma de Español como Lengua Extranjera (DELE) que estipula el Instituto Cervantes. Los puntos obtenidos por los estudiantes determinan el nivel de conocimientos de la lengua y el curso al que deben asistir.

La participación en este estudio fue voluntaria y anónima siguiendo la misma temática para todos: ¿Por qué estudias español? La razón que lleva a la elección de este tema proviene de las conclusiones del estudio realizado por Littlemore et al. (2014) en el que consta que los aprendientes producen un número mayor de metáforas en el momento que son instados a dar opiniones personales sobre temas concretos o a recalcar la importancia que merece un hecho a nivel personal. Además, se especifica que en los tramos de interlengua en la que los aprendientes no expresaban su opinión, el uso metafórico se reducía principalmente a preposiciones (McArthur 
2017: 419). Asimismo, la elección del tema posibilita que todos los participantes, independientemente del nivel, puedan alcanzar la extensión deseada. Si por el contrario, el tema requiere de un vocabulario y unas estructuras gramaticales que pertenecen a niveles avanzados, los participantes de niveles más bajos no serían capaces de llegar a una extensión que posibilite el análisis metafórico y la comparación con otros niveles.

Una vez recolectadas las muestras escritas, se aplicó el método MIP para identificar las expresiones metafóricas de los textos. Como instrumento de medición de la densidad metafórica se empleó la fórmula de Acquaroni (2007). La densidad metafórica se midió de manera individual y seguidamente se realizó la media aritmética de todos los escritos de cada grupo. De esta manera, se pueden sacar conclusiones generales acerca de la densidad metafórica dependiendo del nivel de los participantes y se pueden determinar los índices más altos y más bajos de cada uno de los grupos.

\subsection{Características de los participantes}

Los participantes de esta investigación son estudiantes de las titulaciones de Economía Internacional y Turismo pertenecientes a la Universidad de Ciencias Aplicadas de Heilbronn (Alemania). La edad de los participantes oscila entre los 19 y los 25 años y su lengua materna es el alemán. La combinación de lenguas extranjeras de los participantes de este estudio era inglésespañol. La elección del español como segunda lengua extranjera es optativa ya que tienen la posibilidad de escoger entre árabe, ruso, francés y español. En todos los niveles, la carga lectiva de la segunda lengua extranjera es de cuatro horas pedagógicas a la semana.

El nivel A1 ha sido excluido de este estudio por considerar que al ser el nivel de acceso, los estudiantes no tienen aún el conocimiento necesario para escribir una redacción de unas 150 palabras sin emplear fuentes de consulta y con un tiempo limitado. Igualmente, el máximo nivel de la escala del MCER, el C2, no ha podido ser incluido en esta investigación por el hecho de que no se oferta en la universidad. Sin embargo, los cuatro niveles en lo que se centra este estudio abarcan los tres tipos de usuario que estipula el MCER: básico, independiente y competente. Los niveles A1 y A2 pertenecen a la categoría de usuario básico, los niveles B1 y B2 pertenecen a la de usuario independiente, mientras que los niveles $\mathrm{C} 1$ y $\mathrm{C} 2$ se engloban dentro de la categoría de usuario competente.

Los niveles estipulados en el MCER son el resultado de un proyecto impulsado por el Consejo de Europa en los años 90 cuya primera versión se dio a conocer en el año 2001. La segunda versión más completa con nuevos descriptores como la mediación, la interacción a través de internet y la competencia plurilingüe y pluricultural se ha publicado en el año 2017. Hoy en día, este marco no solo goza de aceptación en el ámbito europeo sino que es usado también en otras zonas geográficas del mundo. Tomando como referencia el enfoque orientado a la acción, dentro de este marco, los usuarios de una lengua son vistos como agentes que pertenecen a una sociedad en la que deben desenvolverse en distintas situaciones empleando la lengua meta.

Según las destrezas comunicativas, la escala global del MCER estipula que en el nivel A2, los aprendientes son capaces de realizar intercambios de información sencillos y directos sobre 
temas que les son conocidos. Además, comprenden frases y expresiones frecuentes y son capaces de dar información básica sobre sí mismos y su entorno social. Los aprendientes de los niveles B1 y B2 están considerados como usuarios independientes. Dentro de esta categoría, en el nivel B1, los aprendientes son capaces de producir textos coherentes sobre temas que les resultan familiares y comprenden las ideas principales de textos con una estructura clara. Además, son capaces de justificar sus opiniones o explicar sus planes. En el nivel B2, son capaces de comprender textos complejos independientemente del tema que traten. Pueden relacionarse con hablantes nativos de manera fluida y pueden producir textos claros y detallados sobre temas diversos, así como defender un punto de vista general. Por último, en el nivel C1, que ya pasa a la categoría de usuario competente, el aprendiente es capaz de comprender una amplia variedad de textos extensos con un vocabulario y unas estructuras gramaticales complejas, así como reconocer dobles sentidos implícitos. El aprendiente sabe expresarse de forma fluida y espontánea. Puede hacer un uso flexible del idioma con fines sociales, académicos y profesionales. Puede producir textos claros, bien estructurados y detallados sobre temas de cierta complejidad, mostrando un uso correcto de los mecanismos de organización, articulación y cohesión del texto.

\section{$4 \quad$ Resultados}

Los participantes del estudio con nivel A2 escribieron 2076 palabras en total mostrando una densidad metafórica media del 5,53\%. En cuanto a la densidad metafórica individual de cada escrito, el valor más bajo es de un 4,72\%, mientras que el más alto muestra un índice del $6,22 \%$. En este caso, las expresiones metafóricas que emplea el estudiante son todas convencionales o muertas. Aparte del uso de preposiciones, las expresiones que metaforizan el tiempo son las más abundantes a lo largo del escrito como dentro de tres semanas, hasta un año o mi tiempo será corto. Además, aparece una expresión metafórica que hace alusión al idioma español otorgándole cualidades de un lugar como la posición central del español. Por último, la única metáfora novedosa del grupo A2 se ha encontrado en este mismo escrito en el que el estudiante afirma que el español es una melodía.

El alemán como lengua materna ha desempeñado un papel fundamental ya que ha dado lugar a errores de transferencia léxica cometidos debido a los falsos amigos entre los dos idiomas. Un ejemplo que se ha repetido en dos ocasiones en escritos de diferentes participantes ha sido la carta* del mundo. Este error está motivado por la proximidad léxica de la palabra española carta y la alemana Karte, que se refiere a mapa. Además, existen asimismo tres estudiantes que apuntan que en el futuro quieren un trabajo en una firma internacional relacionada con el mundo hispánico. Si bien el uso de la palabra firma no es incorrecto, el uso de la palabra empresa está más extendido en este ámbito. Además, la elección de esta palabra se debe a un calco del alemán, ya que Firma significa en español empresa y por lo tanto, se incluye también en la categoría de falso amigo.

En el grupo B1, la suma de todos los escritos tiene una extensión de 2004 palabras y una densidad metafórica del 6,48\%. El escrito que presenta la densidad metafórica más baja es del $4,35 \%$ reduciéndose únicamente a preposiciones y a expresiones idiomáticas, mientras que la densidad más alta de este grupo se encuentra en un 7,73\%. En este caso, todas las expresiones 
metafóricas de las que ha hecho uso el estudiante han sido igualmente convencionales o muertas y provienen en su mayoría de metáforas orientacionales (Lakoff/Johnson 1980). En este tipo de metáforas, los dominios fuente están basados en la orientación espacial y se apoyan en dicotomías como arriba-abajo, dentro-fuera, delante-detrás. Los ejemplos del corpus son: hay que adelantarse, el nivel de español debe ser alto o te deben subir el salario si hablas inglés y español. El número de metáforas novedosas es mucho más reducido, ya que se limita a dos casos. En uno de ellos, un estudiante afirma que está estudiando español con mucha marcha y en el segundo caso, otro estudiante ha escrito el español es mi corazón.

En cuanto a las interferencias del alemán, existen diversos casos en los que los calcos de la lengua materna han dado lugar a expresiones antinaturales por falta de fluidez conceptual. Por ejemplo, en la oración no tuve español durante dos años y me faltaba muchísimo, el uso del verbo faltar en este contexto en vez de la expresión mucho más natural de echar de menos o echar en falta viene producido por un calco de las estructuras del alemán, ya que el verbo fehlen (faltar) se utiliza para comunicar que se echa algo de menos. Otro error metafórico que aparece debido al calco del sistema conceptual que subyace en la lengua alemana es el siguiente: Así podría recolectar muchas experiencias. Mientras que en alemán la experiencia es algo que se recolecta mediante el uso de la expresión Erfahrungen sammeln, en español la experiencia se gana y de ahí proviene el calco de estructuras en el grupo B1. Siguiendo con este ejemplo, es preciso recalcar que en el grupo B2 se ha usado la misma expresión de manera correcta en español con el verbo ganar, lo que indica que, según la Hipótesis de la Fluidez Conceptual de Russo (1997), el estudiante ya accede directamente al sistema conceptual de la lengua meta sin hacer uso de la traducción de estructuras de una lengua a otra.

Después del análisis de los escritos del grupo B2 con 2024 palabras, queda evidenciado que la densidad metafórica es algo más alta que el grupo B1 con una media de 8,15\%. El escrito que presenta la densidad metafórica más alta es de 9,45\% en contrapartida al más bajo con 5,92\%. Las metáforas novedosas de este grupo son más abundantes que las del B1. Por ejemplo, se encuentran expresiones sobre el idioma español que lo definen como el camino para conocer culturas, una parte de mí y al igual que en grupo A2, se repite la metáfora que compara el español con una melodía.

Los errores metafóricos debidos a calcos de la lengua materna siguen apareciendo al igual que en los demás niveles. Por ejemplo, un estudiante utiliza la siguiente oración: hablando español, la comunicación en muchos países me *caerá más fácil. Mientras que en alemán las cosas caen fáciles o difíciles mediante la expresión leicht/ schwer fallen, en español no se hace uso de esa metáfora a través del verbo caer, sino que se utiliza simplemente el verbo ser. Otro de los errores provenientes de un calco de estructuras del alemán se desprende de la siguiente frase: me gustó la imaginación de hablar esta lengua. El estudiante quería transmitir el hecho de que le gustó la idea de hablar esta lengua. Mediante el uso de la palabra imaginación se da por hecho que el estudiante ha hecho uso del sustantivo Vorstellung de su lengua materna, ya que se emplea tanto para referirse a la imaginación en sí, como para crearse una idea concreta acerca de algún asunto en particular. Por lo general, el uso correcto de metáforas convencionalizadas se vuelve más abundante que en los otros dos grupos, lo que muestra un nivel más alto de fluidez conceptual y unas estructuras que se van acercando más a las producciones de los hablantes nativos. Por 
ejemplo, uno de los estudiantes afirma que le resultó difícil tomar la decisión de estudiar español o francés. En alemán, para comunicar que se ha tomado una decisión, se utiliza el verbo treffen. Este verbo tiene diversas acepciones dependiendo del contexto en el que aparece y se utiliza con el significado de encontrarse o coincidir, así como también se utiliza con el sentido de afectar emocionalmente algún hecho particular. Si bien en el idioma alemán las decisiones se encuentran, en el idioma español se toman. Por lo que la fluidez conceptual del estudiante le ha llevado a utilizar la forma correcta. En otra ocasión, un estudiante del grupo B2 afirma que el español encaja con los estudios sobre Turismo. Este estudiante ha hecho un uso correcto y adecuado del verbo con sentido metafórico, en comparación con otro estudiante de nivel A2 que quería expresar la misma idea mediante la oración: el español va bien con mis estudios de Turismo. Poniendo atención a las dos expresiones, se observa que el grado de fluidez conceptual de los dos estudiantes varía. En la primera, el estudiante es conocedor de la forma correcta de metaforizar el concepto de la lengua española mostrando además una producción idéntica a la de cualquier hablante nativo. En la segunda, el estudiante todavía no conoce la forma de metaforizar ese concepto para expresarse correctamente en la lengua meta, por lo que hace uso de una expresión muy general como ir bien.

Por último, en el grupo $\mathrm{C} 1$ se han contabilizado 2062 palabras en total con una densidad metafórica del 11,44\%. En cuanto a la densidad metafórica individual de los escritos, el índice más bajo es de $9,56 \%$ y el más alto es de $14,59 \%$. El uso de metáforas novedosas también se ha hecho notable a lo largo de los escritos. Entre ellas, se encuentran expresiones como el español es el puente entre culturas, la fusión entre las lenguas románicas y el inglés y la puerta de la internacionalización de las empresas. Además, existe otra metáfora novedosa en la que el estudiante escribe que saber idiomas es como tener unas gafas para ver el mundo de otra manera. En cuanto a los calcos de la lengua materna, se encuentran dos casos que afectan levemente a la fluidez conceptual. El primero es el caso de un estudiante que afirma haber trabajado en una guardería apoyada por el Gobierno de México. Cuando el estudiante emplea la palabra apoyada, se refiere a que esa guardería estaba financiada por el Gobierno de México. Por lo tanto, se ha basado en el verbo alemán unterstützen y en sus acepciones para así emplear el verbo apoyar en español. El verbo alemán tiene un significado mucho más amplio, ya que se emplea no solo para las acepciones del verbo español apoyar, sino que adopta igualmente un sentido económico. Por lo tanto, en español, para expresar que hay iniciativas que reciben soporte económico gubernamental se puede decir metafóricamente que están impulsadas por el Gobierno aparte de otras posibles expresiones lingüísticas de los hablantes nativos como financiadas, fomentadas, promovidas o incentivadas. Otra de las expresiones lingüísticas metafóricas del grupo C1 de la que se desprende una leve falta de fluidez conceptual es la siguiente oración: la globalización va a ganar en importancia en el futuro. Si bien gramaticalmente la expresión no es incorrecta, existe una leve diferencia entre el alemán y el español. Mientras que en español, la forma correcta sería crecer en importancia o simplemente ganar importancia omitiendo la preposición en que ha empleado el estudiante, en alemán, por el contrario sí que se utiliza esta expresión con el verbo ganar y con preposición, es decir an Wichtigkeit gewinnen.

Por lo tanto, se constata que en este estudio llevado a cabo con 60 estudiantes alemanes de ELE de cuatro niveles consecutivos, el índice de densidad metafórica aumenta paralelamente con el nivel de la lengua, por lo que es una característica común en los estudios de este ámbito. 
La tabla siguiente (2) ofrece una síntesis de los resultados del análisis:

\begin{tabular}{|c|c|c|c|}
\hline Grupo & $\begin{array}{c}\text { Unidades } \\
\text { léxicas en total }\end{array}$ & $\begin{array}{c}\text { Unidades léxicas } \\
\text { con carga metafórica }\end{array}$ & $\begin{array}{c}\text { Densidad } \\
\text { Metafórica ( \%) }\end{array}$ \\
\hline A2 & 2076 & 115 & $5,53 \%$ \\
\hline B1 & 2004 & 130 & $6,48 \%$ \\
\hline B2 & 2024 & 165 & $8,15 \%$ \\
\hline C1 & 2062 & 236 & $11,44 \%$ \\
\hline
\end{tabular}

Tabla 2: Resultados del análisis

La siguiente ilustración (1) muestra los resultados del estudio mediante un gráfico de barras:

\section{Densidad metafórica}

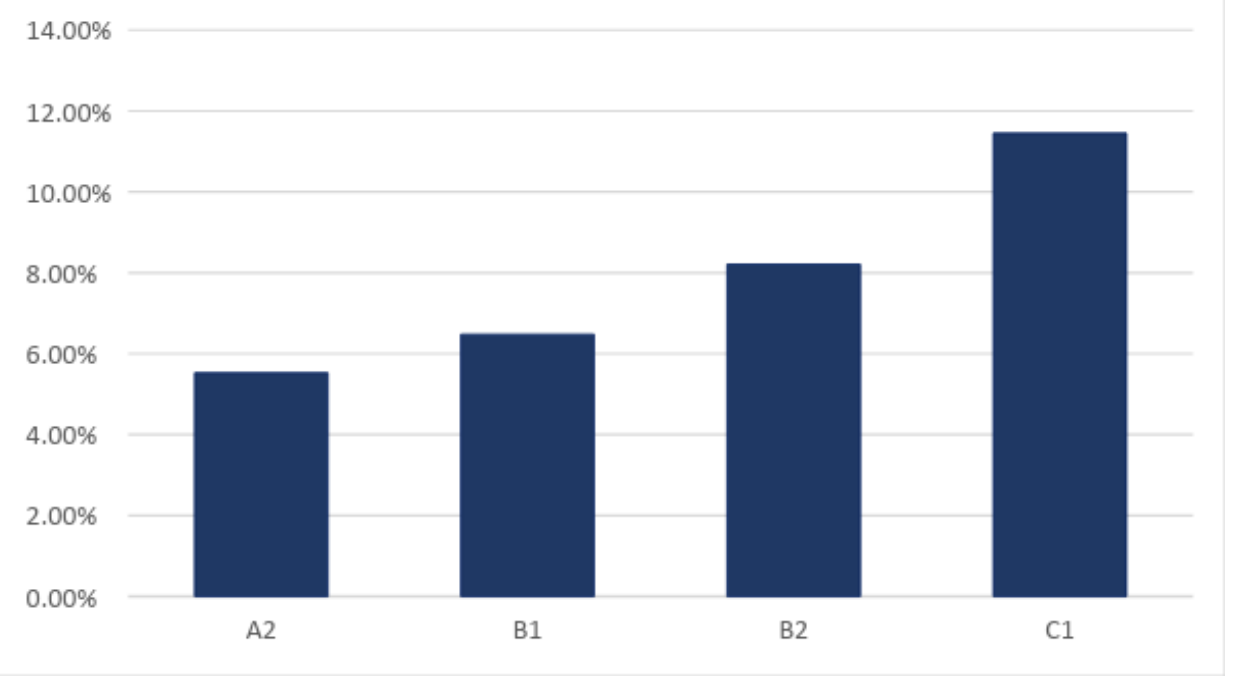

Gráfico 1: Resultados del análisis

\section{$5 \quad$ Conclusiones del estudio y discusión}

Además del hecho de que la densidad metafórica aumenta con el nivel de la lengua de los aprendientes, en este estudio la diferencia de densidad metafórica entre un nivel y otro también va haciéndose mayor conforme aumenta el nivel, ya que entre el grupo A2 y B1 el índice de densidad metafórica difiere un 0,95\%, entre el B1 y el B2 un 1,67\% y entre el B2 y C1 el $3,29 \%$, representando así la mayor diferencia entre niveles.

Los resultados obtenidos varían con respecto a los del estudio de Littlemore et al. (2014) con estudiantes de inglés como lengua extranjera (ILE) cuya lengua materna es el alemán. En primer lugar, la densidad metafórica que obtuvo el grupo de nivel A2 de su estudio es de 2,13\% frente al 5,53\% de este trabajo. Por el contrario, tanto el nivel B1 como el B2 del estudio de Littlemore et al. (2014) representan porcentajes muy similares, el 11,11\% y el 11,62\% respectivamente en comparación con el 6,48 \% y 8,15\% del presente trabajo. Por último, en el nivel C1, los aprendientes de ILE muestran un índice de 16,05\%, bastante mayor que el 11,44\% que obtuvieron los participantes de este estudio. 
La conclusión que se desprende de los resultados obtenidos en ambos estudios es que mientras que la lengua materna juega un papel fundamental en la tipología de las metáforas y en los errores metafóricos, los factores cuantitativos como el índice de densidad metafórica pueden variar también dependiendo de la lengua meta y la temática de los escritos. Las muestras de interlengua que se analizaron en el trabajo de Littlemore et al. (2014) se centran en temas económicos y políticos.

Uno de los trabajos más destacados sobre densidad metafórica en aprendientes de ELE es el de Acquaroni (2007). Esta autora compara la evolución de la competencia metafórica de dos grupos de estudiantes americanos de nivel avanzado. Para ello, llevó a cabo un estudio comparativo en el que separó a los participantes en dos grupos. Uno de ellos era el de control y el otro el de prueba, con el que realizó un taller de escritura creativa. Por medio de un pre-test y un post-test al inicio y al final del cuatrismestre, midió la densidad metafórica de los dos grupos y se pudo constatar la eficacia del taller de escritura. Los resultados de su estudio muestran que mientras que al comenzar el estudio, la DM de los dos grupos oscilaba entre el $7 \%$ y el $8 \%$, el grupo de prueba consiguió llegar casi al $12 \%$, mientras que el grupo de control se quedó en menos del $9 \%$.

Si bien en este estudio el objetivo ha sido observar la evolución natural de la densidad metafórica dependiendo del nivel, el índice de DM de los participantes americanos del estudio de Acquaroni (2007) son equiparables a los niveles B2 y C1 del presente trabajo. Por lo tanto, de esta comparación se reitera la conclusión anterior de que el índice de densidad metafórica puede estar relacionado con la lengua meta de los escritos, mientras que la lengua materna está más relacionada con la tipología de las metáforas que usan los aprendientes. Lo que supondría que las variables cualitativas dependen de la lengua nativa mientras que los valores cuantitativos guardan relación con la lengua meta.

La siguiente conclusión está relacionada con la importancia de las metáforas convencionales para el correcto desarrollo de la fluidez conceptual. Si bien en la literatura no se hace una distinción clara entre metáfora muerta y metáfora convencional, es de crucial importancia recalcar esta distinción, especialmente al aplicar la TMC a la rama de la enseñanza-aprendizaje de segundas lenguas. El razonamiento de esta afirmación radica en que buena parte de las metáforas muertas muestran un grado alto de generalidad si se comparan con otras lenguas. Un ejemplo de ello serían los adverbios de lugar dentro y fuera que se emplean para determinar periodos de tiempo. De ahí viene la expresión dentro del plazo establecido, muy común a distintos idiomas como el alemán innerhalb der Frist, within the stipulated time en inglés, dans le délai prévu en francés y entro il termine prescritto en italiano. Otro ejemplo de la generalidad de las metáforas muertas se encuentra asimismo en las preposiciones. Por ejemplo, el uso extendido de la preposición bajo cuando se utiliza la expresión bajo esas circunstancias, también es compartida por varios idiomas como el alemán unter diesen Bedingungen y el inglés under these circunstances. Por lo tanto, la mayoría de las metáforas muertas que se han analizado en este estudio han presentado un alto grado de lo que Danesi (2003) denomina isomorfismo entre el español y el alemán, ya que coinciden tanto en el plano conceptual como en el plano lingüístico.

Las metáforas convencionales, en comparación con las metáforas muertas, muestran un grado más bajo de generalidad constituyendo así un reto cognitivo mayor para el aprendiente. De ahí 
que los ejemplos más significativos del estudio en cuanto a falta de fluidez conceptual hayan estado ocasionados por copiar las metáforas convencionales del alemán para plasmarlas en el texto español. Por ejemplo, las decisiones en español se toman al contrario que en el alemán, que se encuentran a través del uso de la estructura eine Entscheidung treffen. Así como tampoco se puede decir que en español algo nos*cae difícil, ya que proviene de un calco del alemán. Estas conceptualizaciones tan cotidianas son las que contribuyen a que el texto se adapte a la naturalidad que persigue el enfoque de la TMC aplicada a la enseñanza-aprendizaje de segundas lenguas. Por consiguiente, los resultados obtenidos subrayan la afirmación de que la esencia del aprendizaje de segundas lenguas reside en el uso correcto de todo tipo de metáforas. Entre ellas, se incluyen aquellas cuyos dominios meta son tan cotidianos como el tiempo, el conocimiento y el compromiso, y al mismo tiempo, las metáforas novedosas que requieren un uso más creativo de la lengua.

Es preciso recalcar que las metáforas novedosas han sido escasas a lo largo de este estudio y que su uso por parte de los estudiantes ha sido más numeroso en los niveles B2 y C1. Además, el correcto uso de metáforas novedosas no ha estado ligado a un mayor índice de densidad metafórica por parte de los participantes del estudio, sino que han representado casos aislados. Además, en los escritos en los que se han dado metáforas novedosas, también han existido casos de errores metafóricos. Estos errores metafóricos son fruto de un uso más creativo de la lengua. Como afirma Littlemore et al. (2014: 139): "What appears to be happening here is an experimental stage around FCE (B2) where learners use metaphor more creatively and, as a result, they make more errors". Sin embargo, en este estudio, los errores metafóricos han sido comunes a todos los niveles y han sido ocasionados igualmente por un uso más creativo de la lengua. Sin embargo, no se ha observado una tendencia más marcada en nivel B2.

Por último, y como ya se ha expuesto anteriormente, es preciso recalcar la necesidad de un enfoque en la enseñanza- aprendizaje de segundas lenguas más centrado en aspectos cognitivos, recalcando la máxima de que las lenguas se componen de forma y significado y que estos dos componentes van intrínsecamente unidos. En clase de lenguas extranjeras, "lo que solemos hacer es enseñar a los alumnos a construir formas lingüísticas que dependen de unos principios formales y que son independientes de su significado" (Llopis García et al. 2012: 11). Esto ocurre por ejemplo con los ejercicios de rellenar huecos en los que el verbo a conjugar aparece en paréntesis. El aprendiente es consciente de que debe escribir un tiempo verbal concreto que viene dado por el enunciado. De ese modo, sin atender al significado, es capaz de rellenar el hueco sin problemas y por lo tanto, de desarrollar el ejercicio de manera exitosa basándose únicamente en la forma y siguiendo la norma de conjugación determinada del verbo.

Es preciso abandonar la idea generativista de que las lenguas se componen de un conjunto de normas rígidas, ya que, cuando introducimos un tema gramatical a través de listados con normas de uso, no podemos evitar que los alumnos cometan errores provocados por una serie innumerable de excepciones de cada norma que escapan al alcance del docente. Por lo tanto, es preciso hacer conscientes a los alumnos de que los idiomas son los vehículos que posibilitan una comunicación exitosa entre individuos y que estos se rigen por metáforas cognitivas que tienen una base experiencial. Es decir, tienden a concretizar los conceptos abstractos para dotarlos de características más cercanas a nuestra experiencia como individuos. 
"Si, tal y como afirma la LC (Lingüística Cognitiva), es imposible hablar sin metáforas, cabe preguntarse: ¿Es posible enseñar una lengua sin ellas?” (Masid 2017: 156). Como afirma Llopis García (2016: 45), la metáfora es una aliada pedagógica crucial para la clase de ELE y sus estudiantes porque nos permite a todos descubrir que aunque nuestros idiomas pueden ser lingüísticamente diferentes, conceptualizan el mundo de una manera mucho más similar de lo que nos imaginamos. De esta manera, es preciso enseñar los principios de la TMC en el aula de lenguas extranjeras y hacer conscientes a los aprendientes de que su lengua materna también está repleta de metáforas y expresiones idiomáticas (Ungerer/Schmid 2006: 329). Por lo tanto, a través de la comparación de su lengua materna con la lengua meta, se contribuye a que el aprendiente sea capaz de plasmar las metáforas utilizando la forma lingüística adecuada.

\section{Referencias bibliográficas}

Acquaroni, Rosa (2008): La incorporación de la competencia metafórica (CM) a la enseñanza - aprendizaje del español como segunda lengua (L2) a través de un taller de escritura creativa: un estudio experimental. Tesis Doctoral. Madrid: Universidad de Alcalá de Henares.

Al-Hasnawi, Ali R. (2007): “A Cognitive Approach to Translating Metaphors”. Translation Journal, 11/3. http://translationjournal.net/journal/41metaphor.htm [08.11.2018].

Andreou, Georgia/Galantomos, Ioannis (2008): "Designing a conceptual syllabus for teaching metaphors and idioms in a foreign language context". Porta Linguarum 9: 69-77.

Bachman, Lyle F. (1990): Fundamental considerations in language testing. Oxford: Oxford University Press.

Battle, Jaume (2014): "El amor es como la guerra: es fácil empezar, pero difícil terminar". Rutaele 9: 11-22.

Boers, Frank (2014): “Idioms and phraseology”. In: Taylor, John/Littlemore, Janette (eds.): The Bloomsbury Companion to Cognitive Linguistics. London, Bloomsbury: 185-201.

Boers, Frank (2000): "Metaphor awareness and vocabulary retention". Applied Linguistics 21: 553-571. doi: org/10.1093/applin/21.4.553.

Boers, Frank (2001): "Remembering figurative idioms by hypothesising about their origin". Prospect 16/3: 35-43.

Bylund, Emanuel/Konke, Linn Andersson (2015): "Las metáforas espacio-temporales y la percepción del tiempo: un estudio comparativo sobre el español y el sueco". In: Engwall, Günnel/Fant, Lars (eds.): Festival Romanistica. Contribuciones lingüísticas - Contributions linguistiques - Contributi linguistici - Contribuições linguísticas. Estocolmo, Stockholm University Press: 113-130.

Cai, Yiran (2013): Metaphor in Second Language Teaching and Learning. Tesis de máster. Pennsylvania: Pennsylvania State University.

Cameron, Lynne/Deignan, Alice (2006): "The emergence of metaphor in discourse". Applied Linguistics 27/4: 671-690.

Cameron, Lynne/Stelma, Juurd H. (2004): "Metaphor clusters in discourse". Journal of Applied Linguistics 1/2: 107-136.

Cameron, Lynne (2003): Metaphor in educational discourse. London/New York: Continuum. 
Cameron, Lynne/Low, Graham (eds.) (1999): Researching and applying metaphor. Cambridge, Cambridge University Press: 81-104.

Canale, Michael (1983): "From communicative competence to communicative language pedagogy”. In: Richards, Jack/Schmidt, Richards (eds.): Language and communication. London, Longman: 2-27.

Charteris-Black, Jonathan (2004): Corpus Approaches to Critical Metaphor Analysis. New York: Palgrave-MacMillan.

Cooper, Thomas C. (1999): "Processing of Idioms by L2 Learners of English". TESOL 33: 233-262. http://tesol.aua.am/TQD_2000/TQD_2000/Tq_d2000/Vol_33_2.pdf\#page=58 [08.11.2018]

Danesi, Marcel (1986): "The role of metaphor in second language pedagogy". Rassegna Italiana di Linguistica Applicata 18/3: 1-10.

Danesi, Marcel (1988): The development of metaphorical competence: A neglected dimension in second language pedagogy. In: Mancini Albert. N/Giordano, Paolo/Baldini, Pier Raimondo (eds.): Italiana. Selected papers from the proceedings of the Third Annual Conference of the American Association of Teachers of Italian. River Forest, IL 3: 1-10.

Danesi, Marcel (1991): "Metaphor and classroom second language learning". In: Beer, Jeanette/ Ganelin, Charles/Tamburri, Anthony J. (eds.): Romance Languages Annual 3: 189-194.

Danesi, Marcel (1992): "Metaphorical competence in second language acquisition and second language teaching: the neglected dimension". In: Alatis, James E. (ed.): Language, communication, and social meaning. Washington D.C., Georgetown University Press: 489-500.

Danesi, Marcel (1994): "Recent research on metaphor and the teaching of Italian". Italica 71/4: 453-64.

Danesi, Marcel (1995): "Learning and teaching languages: the role of 'conceptual fluency"'. International Journal of Applied Linguistics 5/1: 3-20.

Danesi, Marcel (1998): “Conceptual iconicity and grammatical rules: towards a reflexive grammar". In: Pencak, William/ Lindgren, Ralph (eds.): New approaches to semiotics and the human sciences: essays in honor of Roberta Kevelson. New York, Peter Lang: 241-264.

Danesi, Marcel (2002): La metafora nel pensiero e nel linguaggio. Brescia: La Scuola.

Danesi, Marcel (2003): Second language teaching. A view from the right side of the brain. Dordrecht: Kluwer Academic Publishers.

Danesi, Marcel (2016): "Conceptual Fluency in Second Language Teaching: An Overview of Problems, Issues, Research Findings, and Pedagogy". International Journal of Applied Linguistics and English Literature 5/1: 145-153.

Deignan, Alice/Gabrys, Danuta/Solska Agnieszka (1997): “Teaching English metaphors using cross-linguistic awareness-raising activities". ELT Journal 51/ 4: 352-60.

Deignan, Alice (2017): "From linguistic to conceptual metaphor". In: Semino, Elena/ Demjén, Zsófia (eds.): Routledge Handbook of Metaphor and Language. New York, Routledge: 102117.

Đoan Ha, Hoàng Thi (2015): Metaphorical language in second language learners' Essays: Products and Processes. Tesis Doctoral. Wellington: Victoria University of Wellington.

Gardner, Howard (1983): Frames of mind: The theory of multiple intelligences. New York: Basic Books. 
Gibbs, Raymond (2006): "Metaphor Interpretation as Embodied Simulation". Mind and Language 21/3: 434-458.

Gibbs, Raymond (1994): The Poetics of Mind: Figurative Thought, Language, and Understanding. Cambridge: Cambridge University Press.

Hashemian, Mahmood/Talebi Nezhad, Mohammad (2007): “The development of conceptual fluency and metaphorical competence in L2 learners". Linguistik Online 30: 41-6.

Herrmann, Berenicke (2013): Metaphor in academic discourse, linguistic forms, conceptual structures, communicative functions and cognitive representations. Utrecht: LOT.

Johnson, Janice/Pascual-Leone, Juan (1989): "Developmental levels of processing in metaphor interpretation". Journal of Experimental Child Psychology 48: 1-31.

Khoshniyat, Arefeh Sadat/Dowlatabadi, Hamid Reza (2014): "Using Conceptual Metaphors Manifested in Disney Movies to Teach English Idiomatic Expressions to Young Iranian EFL Learners". Procedia - Social and Behavioral Sciences 98: 999-1008.

Kecskés, István/Papp, Tünde (2000a): Foreign language and mother tongue. Mahwah (NJ): Lawrence Erlbaum Associates.

Kecskés, István/Papp, Tünde (2000b): "Metaphorical competence in trilingual language production" In: Cenoz, Jasone/Jessner, Ulrike (eds.): English in Europe: the acquisition of a third language. Clevedon, Multilingual Matters: 99-120.

Kövecses, Zoltán (2005): Metaphor in Culture: Universality and Variation. New York: Cambridge University Press.

Lakoff, George/Johnson, Mark (1980): Metaphors we life by. Chicago: Univ. of Chicago Press.

Lakoff, George/Johnson Mark (1996, 1. a ed. 1980): Metáforas de la vida cotidiana. Madrid: Cátedra.

Lakoff, George (1993): “The contemporary theory of metaphor”. In: Ortony, Andrew (ed.): Metaphor and thought. Cambridge, Cambridge University Press: 202-251.

Lamarti, Rachid (2011): La conceptualización metafórica en aprendientes sinófonos de E/LE. Tesina de máster. Universidad de Barcelona. Disponible en el número 5 de Sinoele (www .sinoele.org).

Lamarti, Rachid (2014): La metáfora y la competencia conceptual en estudiantes sinófonos de ELE. Selección de artículos del II Congreso de Español como Lengua Extranjera en AsiaPacífico (CE/LEAP).

Liu, Meihua (2006): “Anxiety in Chinese EFL students at different proficiency levels". System 34/3: 301-316.

Littlemore, Jeanette/Kreynnmar, Tina/Turner, James/Turner, Sarah (2014): “An Investigation into Metaphor use at Different Levels of Second Language Writing”. Applied Linguistics 35/2: 117-144.

Littlemore, Jeanette/Krennmayr, Tina/Turner, James/Turner, Sarah (2012). "Investigating figurative proficiency at different levels of second language writing”. Research Notes 47: 1423.

Littlemore, Janette (2010): "Metaphoric competence in the first and second language: Similarities and differences". In: Pütz, Martin/ Sicola, Laura (eds): Cognitive Processing in Second Language Acquisition. Amsterdam, John Benjamins: 293-316.

Littlemore, Jeanettte/Low, Graham (2006): "Metaphoric competence, second language learning, and communicative language ability". Applied Linguistics 27/2: 268-294. 
Littlemore, Jeanette (2001a): "Metaphoric intelligence and foreign language learning". $\mathrm{Hu}$ manising Language Teaching 3/2: 1-8.

Littlemore, Jeanette (2001b): "Metaphoric competence: a language learning strength of students with a holistic cognitive style?" TESOL Quarterly 35/3: 459-491.

Llopis García, Reyes (2016): “Using Cognitive Principles in Teaching Spanish L2 Grammar". In: Méndez Santos, María del Carmen (ed.). Nuevas perspectivas en la enseñanza del español como lengua extranjera. Hesperia, XIX/2: 29-50.

Llopis García, Reyes/Real Espinosa, Juan Manuel/Ruiz Campillo, José Plácido (2012): Qué gramática enseñar, qué gramática aprender, Madrid: Edinumen.

Low, Graham (1988): “On teaching metaphor”. Applied Linguistics 9/2: 125-147.

MacArthur, Fiona (2017): "Using metaphor in the teaching of second/foreign languages". In: Semino, Elena/Demjén, Zsófia (eds.): Routledge Handbook of Metaphor and Language. New York, Routledge: 413-426.

Maalej, Zouheir (2008): “Translating Metaphor between Unrelated Cultures: A Cognitive-pragmatic Perspective”. Sayyab Translation Journal 1: 60-81.

Martínez Santiago, Fernando/García Cumbreras, Miguel Ángel/ Díaz Galiano Manuel Carlos/ Montejo Ráez, Arturo (2014): "Etiquetado de metáforas lingüísticas en un conjunto de documentos en español". Sociedad española para el procesamiento del lenguaje natural 53: $35-42$.

Masid, Ocarina (2017): "La metáfora lingüística en español como lengua extranjera (ELE). Estudio pre-experimental en tres niveles de competencia”. Porta Linguarum 27: 155-170.

Mellado Blanco, Carmen (1999): "La metáfora en la formación de fraseologismos alemanes y españoles: las metáforas locales”. Paremia 8: 333-338.

Muro, Maritza (2014): La competencia metafórica en el aula de E/LE. Tesis de máster. Estocolmo: Universidad de Estocolmo (Suecia).

Nacey, Susan (2017): "Metaphor comprehension and production in a foreign language". In: Semino, Elena/Demjén, Zsófia (eds.): Routledge Handbook of Metaphor and Language. New York, Routledge: 503-515.

Nacey, Susan (2013): Metaphors in Learner English. Amsterdam/Philadelphia: John Benjamins.

Paivio, Allan/Walsh, Mary (1993): "Psychological processes in metaphor comprehension and memory". In: Ortony, Andrew. (ed.): Metaphor and thought. Cambridge, Cambridge University Press: $307-328$.

Philip, Gill (2005): "From concept to wording and back again: Features of learners' production of figurative language”. In: Barnden, John/Glasbey, Sheila/Lee, Mark/Wallington, Allan/ Zhang Zhang, Lui (eds.): Proceedings of the third interdisciplinary workshop on corpusbased approaches to figurative language. Birmingham: University Press: 46-53.

Pragglejaz Group (2007): "MIP: A method for identifying metaphorically used words in discourse". Metaphor and Symbol 22/1: 1-39.

Rodríguez, Irene/Moreno, Elena (2009): "Teaching idiomatic expressions to learners of EFL through a corpus based on Disney movies". Interlinguistica 18: 240-253.

Russo, Gerard (1997): A conceptual fluency Framework for the Teaching of Italian as a Foreign Language. Tesis Doctoral. Toronto: Universidad de Toronto. 
Saiz de Lobado, María Ester (2015): Prensa e inmigración en España (Comunidad de Madrid) e Italia (Roma): Análisis de la información y análisis metafórico desde una perspectiva estadístico lingüística. Tesis doctoral. Madrid: Universidad de Alcalá de Henares.

Selinker, Larry (1972): "Interlanguage”. IRAL 10: 219-231.

Semino, Elena/Heywood, John/Short, Mick (2004): "Methodological problems in the analysis of metaphors in a corpus of conversations about cancer". Journal of Pragmatics 36/7: 12711294.

Steen, Gerard (1999): "From linguistic to conceptual metaphor in five steps". In: Gibbs, Raymond/ Steen Gerard (eds.): Metaphor in cognitive linguistics. Amsterdam, Benjamins: 5777.

Sullivan, Karen (2013): Frames and Constructions in Metaphoric Language. Amsterdam/Philadelphia: Benjamins.

Trim, Richard (2007): Metaphor Networks. New York: Palgrave-MacMillan.

Ungerer, Friederick/Schmidt, Hans-Jürgen (2006): An introduction to cognitive Linguistics. London: Longman.

Valeva, Gloria (1996): "On the notion of conceptual fluency in a second language". In: Pavlenko, Anete/Salaberry, Rafael (eds.): Cornell Working Papers in Linguistics, Vol. 14: Papers in second language acquisition and bilingualism. Ithaca (NY), Cornell Linguistics Club Publications: 22-38. 